\title{
DA POESIA E DO ‘CATAR’: UMA LEITURA DISCURSIVA`
}

Larissa Scotta**

\section{Introdução}

Neste artigo, objetivamos apresentar algumas reflexões em torno do lançamento de um livro de poemas por uma catadora de lixo reciclável da cidade de Santa Maria, RS. Estas reflexões são parte de trabalho realizado por nós junto ao projeto de pesquisa "Constituir, formular e fazer circular sentidos: dispersão e memória no discurso sobre/na cidade, vinculado ao Laboratório Corpus/UFSM.

Nesse projeto, temos nos colocado questões concernentes à organização das cidades, aos discursos que nela são produzidos, ao modo como os sujeitos se constituem neste espaço social. Entre as questões que nos tocam diretamente quando pensamos a respeito da cidade, uma delas refere-se à presença constante em suas ruas de catadores de lixo reciclável.

O modo de produção capitalista, em sua atual organização, é marcado pela desigualdade, fazendo com que nem todos os cidadãos tenham as mesmas possibilidades e direitos nas esferas econômica e social. Isso ocasiona o que é comumente entendido como "exclusão". Esses sujeitos que não conseguem entrar no mercado de trabalho e, portanto, fazer parte da engrenagem capitalista, buscam sua sobrevivência de diversas formas, uma delas por meio da coleta de materiais recicláveis pelas ruas.

Cabe ressaltar que quando nos referimos à exclusão não estamos falando a partir do conceito tradicional que afirma que existem excluídos que precisam ser incluídos no sistema pois, para nós, os 'ditos' excluídos, na verdade já estão incluídos na lógica do capital. Procuraremos, desta forma, trabalhar nesse texto com a questão da exclusão a partir de um entendimento de que os catadores de lixo, em sua grande maioria, estão excluídos de sua condição humana e que muitas vezes a sua valorização, 0

Texto elaborado no ano de 2004.

** Mestre em Letras/Estudos Lingüísticos pela UFSM. 
reconhecimento de sua atividade pode significar um passo na busca de uma vida mais humanizada.

Acreditamos que não há uma boa aceitação por parte da maioria dos catadores em viver do lixo, pois embora seja muito significativo o número de famílias que sobrevivam da coleta de lixo reciclável em todo o país, essa atividade é marcada, muitas vezes, pelo preconceito que os estigmatiza e os coloca numa posição discriminatória.

Entendemos, também, que essa posição social dos catadores de lixo pode vincular-se ao conceito de 'cidadania', já que não ter condições econômicas e sociais de sobrevivência significa, de certa forma, não ser cidadão, não exercer a cidadania.

E é sob esse aspecto que vamos direcionar nosso trabalho, é na confluência desses dois conceitos que trataremos da questão dos catadores de lixo. Também cidadania não é entendida aqui segundo as conceituações mais tradicionais, pois preferimos tratá-la de acordo com Orlandi (2004, p.65), que considera que a cidadania não é uma essência, "que seu sentido não se faz por si mesmo, mas no cruzamento da história e o modo como o social se significa nos sujeitos nos diferentes sentidos da cidade governada pelo Estado".

\section{Delimitando nosso objeto de estudo}

Para Orlandi (2004), a perspectiva da Análise de Discurso difere da antropologia, da sociologia e de outras especialidades que tratam da cidade, pois ela busca analisá-la através do discurso, compreendendo seus processos de significação e relações de sentido. É então, a partir do que é proposto por Orlandi $(2004,2002)$ sobre o urbano e a Análise de Discurso, assim como a partir de noções desenvolvidas por Pêcheux, que encontramos condições teóricas para desenvolvermos nosso trabalho, já que o importante para nós é compreender as práticas discursivas de alguns dos sujeitos urbanos, nesse caso, dos catadores de lixo.

Quando delimitávamos o objeto desse trabalho, na dúvida sobre o que abordar mais especificamente, um fato nos chamou a atenção e fez centrar nosso foco de interesse: o lançamento de um livro de poemas intitulado "Catando Cidadania", pela catadora de lixo Tereza M. da Silva, de 66 anos, da cidade de Santa Maria, interior do estado do Rio Grande do Sul. Esse acontecimento nos instigou a compreender as práticas discursivas dessa catadora, para buscar 
entender como os vocábulos 'lixo', 'poesia' e 'cidadania' reverberam sentidos no discurso produzido pela catadora poeta.

Nosso objetivo ao tratar da 'cidadania' não será o de refletir sobre esse conceito, nem buscar analisar as diversas noções de cidadania que existem, pois procuramos entender, como propõe Orlandi (2004, p.22), "o funcionamento do objeto simbólico, explicitar como ele produz sentidos, (..) mostrar os mecanismos dos processos de significação que presidem a textualização de uma discursividade", no caso da nossa pesquisa, o discurso da catadora Tereza, pois segundo a autora supracitada (2004, p. 24), "o trabalho do analista é em grande medida situar (compreender) - e não refletir - o gesto de interpretação do sujeito na produção do dizer e expor seus efeitos de sentido".

Debruçaremo-nos sobre o discurso de Tereza buscando interpretar não apenas o que foi dito, mas também o que não foi, já que uma das questões que a Análise de Discurso apresenta, conforme observa Orlandi (2002, p.82) é a de que "ao longo do dizer, há toda uma margem de não-ditos que também significam".

Nossos questionamentos principais são: quais os gestos de interpretação que Tereza tem ao falar sobre o lixo, sobre sua vida como catadora e poeta? Quais os sentidos da relação de Tereza com a cidadania? Que sentidos outros surgem do lançamento de seu livro? Em qual ou quais formações discursivas o discurso de Tereza se funde?

Para trilharmos um caminho em direção a respostas possíveis a estas questões, fizemos uma entrevista com Tereza, a qual citaremos em determinados momentos neste trabalho. Além disso, outras informações relevantes concernentes à catadora foram encontradas em uma matéria do Jornal A Razão*, o qual apresentava Tereza e seu livro "Catando Cidadania".

\section{Uma análise possível}

A catadora Tereza da Silva participa na cidade de Santa Maria do projeto Catando Cidadania. Nesse projeto os catadores formaram um coral e um grupo de teatro, além de terem aulas de dança. Ao perguntamos a Tereza se gostava de participar do projeto, ela foi enfática:

*Edição de Setembro de 2004. 
Olha, eu acho maravilhoso porque sabe que na minha idade eu já estava ficando estressada, porque a minha casa é pequena, (...), falta muita coisa sabe, e se eu ficá em casa pensando a minha casa tem gotera eu não possu comprá brasiliti,(..) o meu sofá quando incendiô a minha casa, né, faz quatro anos que ela ardeu em chama, nós ficamo sem nada, eu digo, lá no coral a gente está ensaiando canto, está ensaiando teatro e parece que aqui pra mim foi uma alegria imensa (...) que a turma é muito unida, né.

O livro "Catando Cidadania" surgiu a partir da sua participação no coral e no teatro. A catadora foi criando poemas que relatavam suas experiências no projeto e, unindo com outros que ela havia criado a algum tempo, apresentou-os à coordenadora do projeto, que Tereza se refere pelo nome de Regina, que viu ali a possibilidade de concretizar o sonho da catadora de escrever um livro.

O lançamento do livro tem como objetivo, de acordo com a coordenadora, "criar um fato", mostrar que o catador de lixo deve ter acesso aos bens culturais e usufruir o espaço oferecido pela Casa de Cultura à comunidade. Segundo Tereza: "se eu não entrasse no coral e não conhecesse irmã Dill, se eu não conhecesse a dona Regina, (...) eu acho que as poesias iriam ficar guardadas e iria se tornar mais difícil". Ela se refere aqui ao lançamento do livro.

De acordo com a catadora, foram os coordenadores do projeto os maiores incentivadores da realização da publicação de Catando Cidadania, inclusive porque quem arcou com os custos da obra foram a Secretaria da Cultura do município e a Igreja Católica, que também coordena o projeto.

Sua ligação com a poesia e o lixo não é recente. Tereza começou a compor a quarenta anos e a catar há vinte. Mas foi depois do incêndio ocorrido em sua casa, no ano de 2001, onde queimaram todos os pertences de sua família, além dos poemas que havia escrito ao longo de sua vida, que ela decidiu ser catadora e escrever com mais freqüência. Depois de passar os dias na rua, Tereza voltava até o galpão onde se abrigava e, por não com o que se distrair, começava a escrever:

Então a casa queimou e eu fiquei sem nada, (...) aí eu comecei a catar com mais freqüência né,(...) aí eu chegava cansada, eu não tinha mesmo um rádio pra escutar, não tinha uma tv pra olhar, então eu pegava o caderno, uma borracha, um lápis e começava a escrever, que a primeira poesia que eu fiz foi da minha vida, de eu 
sair a catar, tudo faz parte da minha vida porque eu saia com frio, com calorão, saía catando, trabalhando, pois é, essa é uma parte muito importante da minha vida.

É interessante o fato de que, ao ser indagada nas entrevistas a respeito de sua atividade, Tereza se mostrou muito determinada, afirmando que realmente gosta de ser catadora: "eu gosto, gosto mesmo, eu ponho as luva e tomo meu banho, me perfumo, às vez até pintá minhas unha de novo eu pinto e vô catá".

Ao mesmo tempo em que faz parte do grupo de catadores, ela se coloca diferente deles, pois como afirma na entrevista, embora conviva com o lixo faz questão de estar 'bem perfumada' e com as 'unhas pintadas'. Uma das marcas de Tereza, segundo ela, é a vaidade. Segundo a catadora: "não precisa andá suja nem encardida, a gente se cuida, eu levo as luva e levo um pano bem limpinho no carrinho, (...) assim como eu saí eu volto pra casa.

Quando perguntamos se ela sofria algum tipo de discriminação, Tereza nos disse que, mesmo sendo sempre educada e estando bem apresentável, muitas pessoas chegavam a atravessar a rua quando passavam por ela.

Tem muita gente que olha assim pra gente(...)só no olharem a gente sente(...)mas pra mim não tem importância, porque eu não tô fazendo nada de errado, eu estô só catando as minhas coisa que eu acho que devo de catá pra ajudá na renda da minha família(...)porque tem gente que quando a gente vai passando assim, tem moças e senhora que vão pro meio da rua, isso que eu nunca fui catá suja (..)

Apesar da discriminação, Tereza não acha que deve parar de catar, pois ela afirma gostar do que faz. Catar, para ela, é uma profissão como outra qualquer. Segundo ela, "enquanto eu tiver pernas para catar e olhos e lápis e borracha pra escrever minhas poesias, tá tudo bem".

Em um de seus poemas, intitulado "A papeleira", a catadora poeta enfatiza que: 
Sou papeleira há 20 anos

lá isso é verdade

vivo lidando com o lixo

mas com muita honestidade

os catadores são humildes

sejam da cor que forem

às vezes discriminados

pela profissão que temos

nós nunca desanimamos nós todos somos humanos

igual a qualquer homem

Deus deu sorte para uns

sacrifício para outros

mas para manter a postura

vivemos muito felizes.

Nesse poema, é possível entender como Tereza vive e o orgulho que tem de ser catadora. O lixo, para ela, não é sinônimo de restos, coisas sem valor, inúteis, é justamente o contrário. Tereza vive do que o lixo lhe oferece. Sua renda é tirada do lixo e sua casa foi reconstruída, após um incêndio, com muito do que ela encontra nos lixos da cidade. Ela mesma valoriza seu trabalho, quer nos poemas, quer nas entrevistas, pois é sempre enfática ao dizer que gosta de catar e que o faz sempre com disposição. Vejamos:

Essa relação entre catar lixo e fazer poesia, vivenciada por Tereza, é para nós um fato relevante, pois foi 'catando' palavras e as unindo em versos que catadora pôde ser reconhecida como cidadã. Todavia, não podemos esquecer que o projeto do qual ela faz parte é o responsável por isso.

Salientamos que a obra Catando Cidadania tem o mesmo nome do projeto do qual Tereza é participante e este título não foi dado por ela, mas pela coordenadora. Perguntamos a ela o porquê do título falar sobre cidadania e ela respondeu:

Olha, porque sabe que, ainda tem muita gente que o catador não tem valor pra eles, não tem importância nenhuma, quando muita gente soube que o livro já estava no forno (..) disse: ahh, tu fazê livro, vendê, pra quê? Aí um dia eu pensei assim, mas quem sabe me dá vontade de desistir... mas eu já me empenhei tanto, então eu continuei fazendo o livrinho.

Ou seja, há uma desvalorização do sujeito catador de lixo e a catadora, mesmo ciente de que seu livro não significava um acontecimento importante para muitas pessoas não desistiu de 
lançá-lo. Uma das leituras que é possível de se fazer é a de que cidadania significa para Tereza ser valorizada por algo que fez, no caso por ter escrito um livro, ainda que haja o descaso de muitos.

Perguntamos-nos então se o fato de Tereza valorizar sua atividade, estar sempre disposta a catar e o fazer sempre com alegria, cuidar da aparência, tem alguma relação com o projeto do qual ela faz parte. Abre-se aqui um espaço para nossa interpretação discursiva.

Entendendo que existe uma relação entre o discurso do sujeito e o discurso do outro e essa identificação/associação relaciona-se às Formações Discursivas, da mesma forma como o sujeito é denominado pela Formação Discursiva na qual ela inscreve seu discurso (Pêcheux, 1997) podemos nos perguntar: qual ou quais Formações Discursivas permeiam o discurso de Tereza? Quais as relações de sentido que podemos identificar na ligação do discurso de Tereza com o do projeto Catando Cidadania?

Para fazermos essa análise é importante também destacarmos o que Orlandi (2002) propõe sobre o interdiscurso. Segundo a autora, o interdiscurso determina o intradiscurso, tudo o que já foi dito e esquecido tem um efeito sobre o dizer que se atualiza em uma formulação. Ou seja, há sempre vários dizeres já constituídos historicamente, que irrompem novamente, de forma a re-significar os enunciados em um determinado momento histórico.

Quando pensamos no discurso de Tereza não há como não relacioná-lo ao discurso do projeto Catando Cidadania, pois muito de sua fala está re-significando, atualizando os dizeres já constituídos pelos responsáveis pelo projeto. Tanto nas entrevistas como nos poemas é possível perceber que são pelo menos estas duas importantes formações discursivas que permeiam o discurso de Tereza: uma relativa ao poder municipal e outra relativa à Igreja Católica.

Quando Tereza afirma em um de seus poemas "Deus deu sorte para uns/ sacrifício para outros/ mas para manter a postura vivemos muito felizes" percebemos que o discurso religioso está muito presente. A questão de aceitar o destino que Deus impõe aos homens (sorte para uns e sacrifício para outros), e viver com alegria apesar das desventuras, atualiza-se no discurso de Tereza.

No projeto Catando Cidadania, a presença da Igreja é muito forte, seja por meio de uma religiosa, Irmã Lurdes Dill, que também é coordenadora, seja porque esse interesse em mostrar ao catador sua importância e a necessidade de aceitar o que acontece como 
destino vincula-se a um discurso de aceitação da posição social que se tem, de valorização das classes menos favorecidas que, segundo a Igreja, não estão nessa condição por culpa da organização da sociedade, mas porque "Deus assim o quis".

Em outro poema de Tereza reconhecemos as marcas desse discurso quando ela declara: "Nós somos catadores, é a nossa profissão. I por falta de estudo, Deus nos deu essa missão". Vejamos: ela afirma que, por não ter estudado, the cabe ser catadora, mas essa "escolha" não é feita por ela, mas por Deus. Aceitar as coisas como são e procurar ser feliz com o que se tem, nada mais condizente com o discurso da Igreja Católica, nada mais condizente com o discurso de Tereza.

Entendemos também que a vontade de Tereza em lançar o livro foi importante, mas o que determinou a publicação de "Catando Cidadania" foi o interesse da Casa de Cultura em mostrar que o catador deve ter acesso aos bens culturais. E qual a razão disso? Não questionamos o fato em si, mas o porquê disso ser feito com tanto entusiasmo. A obra foi lançada na Feira do Livro da cidade, em uma solenidade com Tereza, o prefeito, os coordenadores e integrantes do projeto e a imprensa, além de várias outras pessoas.

O que entendemos a partir da constituição do discurso de Tereza é que o mesmo busca a valorização dos catadores de lixo instituída em um jogo de poder pela prefeitura (no caso petista), de Santa Maria, à procura da inclusão social de grupos considerados excluídos na era da globalização. Essa busca por valorização é aparentemente interessante, pelo fato de que dá oportunidade aos "ditos" excluídos da sociedade, como os catadores, de terem voz e poderem ser reconhecidos como cidadãos. Mas sem dúvida essa vontade de que catadores como Tereza exerçam sua cidadania não é isenta de interesses pré-determinados. O lançamento do livro Catando Cidadania é uma forma de Tereza exercer sua cidadania, mas é também a maneira que a prefeitura encontrou para ressaltar que ela está dando importância a esses sujeitos.

\section{Últimas considerações}

Para concluirmos, alguns aspectos podem ser ressaltados. $O$ primeiro: o lançamento do livro "Catando Cidadania" deve ser considerado não apenas porque se trata de um acontecimento importante que coloca em jogo a valorização do sujeito catador de lixo e torna possível o exercício da cidadania por parte de Tereza, 
mas também porque quando analisamos seu discurso percebemos que as formações discursivas que o determinam se evidenciam de forma latente e essas formações remetem a importantes formas de poder: o político e o religioso.

Segundo: Orlandi (2004, p.90) afirma que: "é preciso dar voz, capacidade de decisão, propiciar a qualificação da cidadania em grande escala". A pergunta que nos colocamos é: até que ponto o projeto Catando Cidadania está dando um passo na busca de que isso se torne realidade?

Mesmo assim, Tereza vai em frente, puxando o carrinho onde recolhe o lixo pela cidade e levando consigo o desejo de uma vida melhor. Uma cama, uma casa repartida, mais um livro lançado. É isso que quer Tereza para que se sinta feliz. Cidadania? Sim, ela se considera cidadã. Catando lixo e fazendo poesia, ela segue em sua batalha diária buscando sobreviver num mundo globalizado pela cultura e pela economia.

\section{Referências bibliográficas}

ORLANDI, E. Cidade dos Sentidos. Campinas: Pontes, 2004.

Análise de Discurso: princípios e procedimentos. 4. ed. Campinas: Pontes, 2002.

PÊCHEUX, M. Semântica e discurso: uma crítica à afirmação do óbvio. 3. ed. Campinas: Editora da Unicamp, 1997. 